\title{
Network Assembled Structures from a Series of Macromolecular Surfactants
}

\author{
X.M. Zhong, W.M. Yao, J.Y. Chen, Y.H. Lai, X.S. Lin, L.J. Kong, X. Wu \\ College of Chemistry and Chemical Engineering \\ Guangzhou University \\ Guangzhou, China
}

\begin{abstract}
Network assembled structures from a series of macromolecular surfactants were prepared on glass surfaces. When the content of the hydrophobic side-chains was increased from 10 to $90 \mathrm{~mol} \%$, the solutions exhibited a lower surface tension. In addition, these solutions ultimately formed thinner and more orderly network-based porous films on glass surfaces.
\end{abstract}

Keywords-associative behaviour; network structures; macromolecular surfactants; hydrophobic side-chains

\section{INTRODUCTION}

The self-assembly behavior of surfactants on solid surfaces is of significant scientific and technological importance due to their relevance to biomacromolecular systems and potential for various industrial applications.[1] Macromolecular surfactants incorporate hydrophilic and hydrophobic monomer units that are attached to the same surfactant backbones,[2] and the selfassembly behavior of these surfactants can be influenced by their inherent structures, concentrations, mixing ratios among multi-component systems, and external stimuli. Generally, the self-assembled nanostructures of macromolecular surfactants can exhibit a wide range of architectural diversity, and these self-assembled nanostructures also tend to be more stable than the self-assembled structures of low molecular weight amphiphiles.[3]

In recent years, the development of surface modification techniques has led to the facile preparation of macromolecular films and facilitated the modification of surfaces.[4] However, the composition and homogeneity of these films were often poorly defined or differed from the expected composition. On solid supports, various kinds of macromolecular structures have been investigated, including those of linear block copolymers,[5] dendronized macromolecules,[6] special macromolecules incorporating siloxane blocks or fluorinated units, and composite macromolecular systems. However, further fundamental studies are required in order to advance our understanding of the formation and structure of macromolecular films.

Our interest in macromolecular surfactants began almost a decade ago, and a novel series of brush-like macromolecular surfactants with different side-chain compositions have been reported.[7-10] In the present work, the morphologies of the self-assembled films prepared from these surfactants with varying hydrophobic side-chain contents (ranging between 10 and $90 \mathrm{~mol} \%$ ) on solid supports were investigated. In addition to the morphologies of the surfactant films, the surface tension of solutions of these surfactants were also investigated. Upon investigating the structures of the films on the surfaces, we were surprised to discover that the surfactant structure had a strong influence on the assembled structures on glass surface. This work will provide valuable insight into the design and preparation of macromolecular films with well-defined functional nanostructures that exhibit tunable properties.

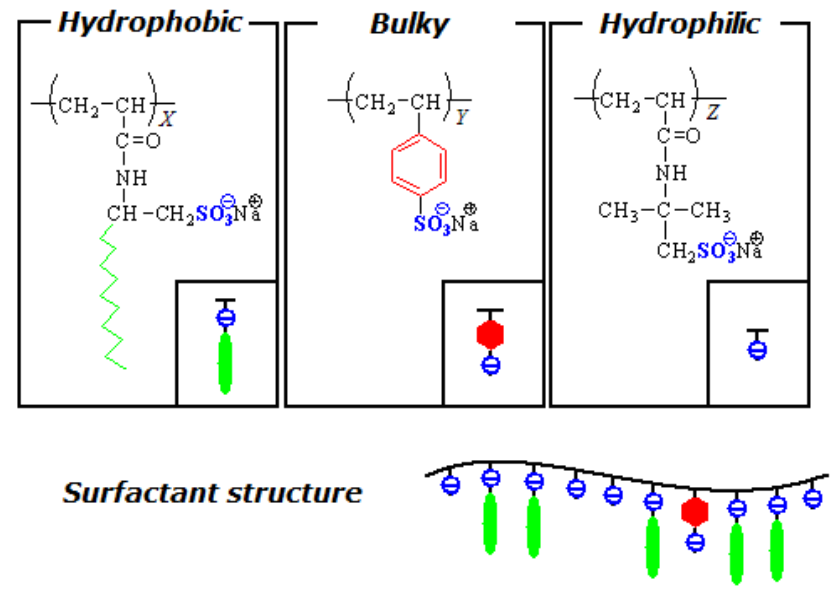

FIGURE I. ILLUSTRATION OF THE MACROMOLECULAR SURFACTANTS THAT INCORPORATED HYDROPHOBIC (AMC12S) UNITS, BULKY (SSS) UNITS, AND HYDROPHILIC (AMPS) UNITS. THE SUBSCRIPTS IN THE STRUCTURES SHOWN ABOVE REPRESENT THE MOL\% VALUES FOR EACH UNIT, WHERE $X=10$ 30, 50, 70, AND 90 MOL\%, Y = 5 MOL\%, AND Z = 95-X MOL\%.

\section{EXPERIMENTAL SECTION}

\section{A. Macromolecular Surfactants}

The macromolecular surfactants incorporating 2(acrylamido)-dodecane sulfonic acid (AMC12S, 10-90 mol\%), sodium p-styrenesulfonate (SSS, $5 \mathrm{~mol} \%$ ), and 2(acrylamido)-2-methylpropane-sulfonic acid (AMPS) units were synthesized, purified, and characterized according to the methods described in our previous report.9.

\section{B. Measurements}

Sample solutions for surface tension, contact angle measurements, and SEM characterization were the same as that investigated in the previous work.9 Surface tension curves of the surfactant solutions were obtained by using the dropvolume method at $25.0 \pm 0.5{ }^{\circ} \mathrm{C}$. The contact angles were measured via axisymmetric drop shape analysis (ADSA) at room temperature. The morphologies of the assembled macromolecular films that had been formed on glass surfaces 
were observed using a Hitachi S-530 scanning electron microscope (SEM).

\section{RESULTS AND DISCUSSION}

The surfactants adsorbed at the air/water interface would interact with the aggregates in the solution phase as the solvent evaporates during the formation of film on the solid surface. The surface tension of the surfactant solutions could provide information about the adsorption of molecules at air/water interface. A plot of the variation of the surface tension versus the surfactant concentration is shown in Figure 2. There is no clear breakpoint for the surfactants with fc12 $=10 \mathrm{~mol} \%$ and fc12 = 30 mol\%, which implies that the adsorption of these two surfactants keep changing along with the increase of concentrations. This also suggests that the associative behavior of the surfactants possessing less of the amphiphilic AMC12S side-chains could have a stronger tendency to change with the increase of concentrations. The surface tensions of the surfactant solutions decreased when the concentrations were increased, indicating the progressive adsorption of the molecules at air/water interface along with the increase of concentrations. In addition, the surface tension of the surfactant solutions decreased when fc12 was increased, indicating that surfactants possessing more side-chains exhibited a lower surface tension.

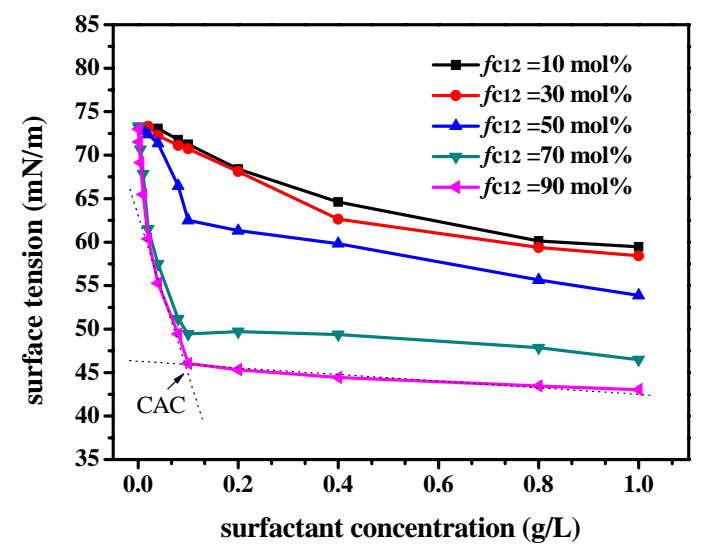

FIGURE II. PLOTS OF SURFACE TENSION AGAINST THE CONCENTRATIONS OF SURFACTANTS WITH VARYING FC12 VALUES.

In Figure 3, the morphologies of the films prepared from surfactants with varying fc12 values are shown. Regardless of their varying molecular structures, it was apparent that all of the surfactants yielded porous network structures. In addition, the arrays of these mesh-like structures became progressively more continuous and orderly for the surfactants with higher fc12 values. The films also became thinner when they were prepared from surfactant solutions that exhibited lower contact angles, and films of the surfactant with fc12 = $90 \mathrm{~mol} \%$ appeared to exhibit a monolayer structure (Figure 3e). As mentioned earlier, this trend suggests that the thickness of the film is directly related to the contact angles of the surfactant solutions. Due to their long range nanoporous structures, the network-based films observed here could have various potential applications, such as gas separation, biosensors, or catalyst supports.

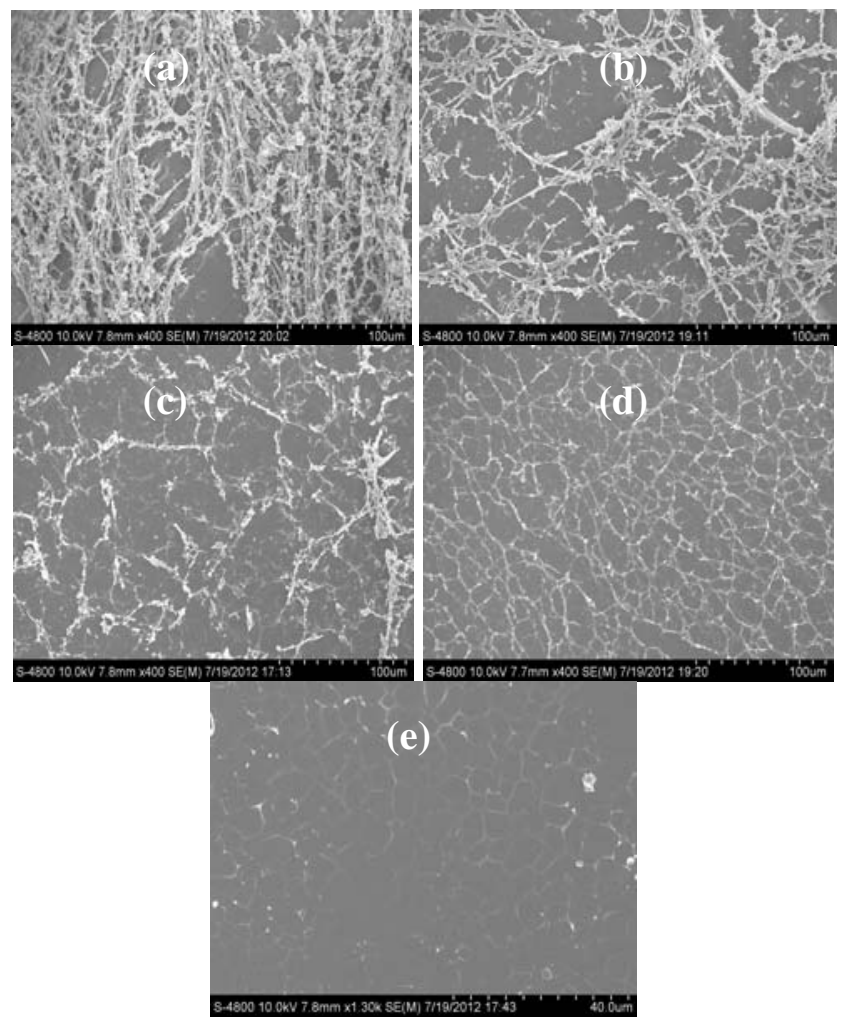

FIGURE III. SEM IMAGES OF SURFACTANT FILMS THAT HAD FORMED ON THE SURFACES OF GLASS SLIDES. THESE FILMS WERE COMPOSED OF SURFACTANTS WITH VARIOUS FC12 VALUES INCLUDING: FC12 = 10 (A), 30 (B), 50 (C), 70 (D), AND 90 MOL\% (E).

\section{CONCLUSIONS}

The solutions of macromolecular surfactants with higher fc12 values would have a lower surface tension, and the solutions of the surfactants described in this report had surface tension in the range of $43-60 \mathrm{mN} / \mathrm{m}$. The surfactant structures have obvious effects on the morphology of the films formed by the surfactants on surface. The solutions of surfactants with higher fc12 values formed thinner and more orderly networkbased porous films covering the surfaces of glass slides, and the long range nanoporous structures of the films may find application in various fields.

\section{ACKNOWLEDGEMENTS}

We acknowledge the financial support from the National Natural Science Foundation of China (Grant No. 21406040) and the Technology Project of Guangzhou (Grant No. 2013J4100023).

\section{REFERENCES}

[1] Sambe, L., Stoffelbach, F., Lyskawa, J., Delattre, F., Fournier, D., Bouteiller, L., Charleux, B., Cooke, G., Woisel, P. Host-Guest Modulation of the Micellization of a Tetrathiafulvalene-Functionalized Poly ( $N$-isopropylacrylamide). Macromolecules, 44, pp. 6532-6538, 2011.

[2] Feng, K., Xie, N., Chen, B., Zhang, L.P., Tung, C.H., Wu, L.Z. Reversible Light-Triggered Transition of Amphiphilic Random Copolymers. Macromolecules, 45, pp. 5596-5603, 2012. 
[3] Moughton, A.O., Hillmyer, M.A., Lodge, T.P. Multicompartment Block Polymer Micelles. Macromolecules, 45, pp. 2-19, 2012.

[4] He, G.P., Hu, J.W., Liu, G.J., Li, Y.H., Zhang, G.W., Liu, F., Sun, J.P., Zou, H.L., Tu, Y.Y., Xiao, D.S. Superhydrophobic Hierarchically Assembled Films of Diblock Copolymer Hollow Nanospheres and anotubes. ACS Applied Materials \& Interfaces, 5(7), pp. 2378-2386, 2013.

[5] Li, X., Yu, X.H., Han, Y.C. Intelligent Reversible Nanoporous Antireflection Film by Solvent-Stimuli-Responsive Phase Transformation of Amphiphilic Block Copolymer. Langmuir, 28(28), pp. 10584-10591, 2012.

[6] Shau, S.M., Chang, C.C., Lo, C.H., Chen, Y.C., Juang, T.Y., Dai, S.A., Lee, R.H., Jeng, R.J. Organic/Metallic Nanohybrids Based on Amphiphilic Dumbbell-Shapped Dendrimers. ACS Applied Materials \& Interfaces, 4(4), pp. 1897-1908, 2012.

[7] Wu, X., Qiao, Y.J., Yang, H., Wang, J.B. Self-Assembly of a series of Random Copolymers Bearing Amphiphilic Side Chains. Journal of Colloid and Interface Science, 349, pp. 560-564, 2010.

[8] Wu, X., Wang, J.B., Yang, H., Shi, X.F. Self-assembly of Brush-like Statistical Amphiphilic Polymers: the Effect of Salt Stimulus on the Molecular Associative Mode. Supramolecular Chemistry, 25(3), pp. 151-157, 2013.

[9] Wu, X., Cai, X.X., Hao, A.H., Wang, J.B. Molecular Design of Brushlike Amphiphilic Statistical Tripolymers and the Self-assembly Behaviors. Journal of Chemical \& Engineering Data, 58, pp. 927-931, 2013.

[10] Wu, C.X., Hou, Y.B., Deng, M.L., Huang, X., Yu, D.F., Xiang, J.F., Liu, Y., Li, Z.B., Wang, Y.L. Molecular Conformation-Controlled Vesicle/Micelle Transition of Cationic Trimeric Surfactants in Aqueous Solution. Langmuir, 26(11), pp. 7922-7927, 2010. 